\title{
Level of Awareness on Danger Signs During Pregnancy and Associated Factors, among Pregnant Mothers, Dire Dawa Administrative Public Health Facilities, Eastern Ethiopia
}

Neil Abdurashid ${ }^{1^{*}}$, Nesredin Ishaq $^{2}$, Ketema Ayele $^{3}$ and Nina Ashenafi ${ }^{4}$

${ }^{1}$ Department of Midwifery, College of Medicine and Health Science, Dire Dawa University, Dire Dawa, Ethiopia

${ }^{2}$ Harari Regional Health Bureau, Harari Regional Health Bureau, Harari, Ethiopia

${ }^{3}$ Department of Medicine, College of Medicine and Health Science, Dire Dawa University, Dire Dawa, Ethiopia

${ }^{4}$ Staff of MCH Midwives, Gendekore Health Centre, Dire Dawa Administrative, Dire Dawa, Ethiopia

"Corresponding author: Neil Abdurashid, Department of Midwifery, College of Medicine and Health Science, Dire Dawa University, Dire Dawa, Ethiopia, T el: +251911833310; E-mail: firdowsayuzarsif@gmail.com

Received date: January 26, 2018; Accepted date: February 20, 2018; Published date: March 07, 2018

Copyright: $@ 2018$ Abdurashid N, et al. This is an open-access article distributed under the terms of the Creative Commons Attribution License, which permits unrestricted use, distribution, and reproduction in any medium, provided the original author and source are credited.

\section{Abstract}

Background: Raising awareness of women on danger signs during pregnancy is crucial for safe motherhood. In Ethiopia a country where maternal morbidity and mortality is high where little is known about awareness level of pregnant women on danger signs of pregnancy is used to enhance utilization of skilled care in low-income countries like Ethiopia.

Objective: To determine level of awareness on danger signs of pregnancy and associated factors among ANC attendant mother in urban and rural health centres, in Diredawa, eastern Ethiopia.

Methods and materials: Facility based cross-sectional study design was used to collect data. The study was conducted among a sample of 502 pregnant women in Diredawa administration town in selected health centres from Jan 1-Mar 30/2017. Sample size was determined by using double population proportion formulas. Simple random sampling technique was used to select six health centres, three from each urban and rural resident. Then systematic random sampling technique was used to select study subjects by considering both the inclusion and exclusion criteria. Pregnant mothers were interviewed face to face using pre-tested structured questionnaire. Data was checked for completeness, consistency and coded before data entry. Data entered, cleaned and analyzed using SPSS for windows version 20.0. Bivariate, multivariable logistic regression model were used to demonstrate the difference between study subjects' characteristics (independent variables) and level of awareness of danger sign of pregnancy.

Results: Of all $502(100 \%)$ respondents interviewed $121(24.1 \%)$ mothers had good awareness of danger signs of pregnancy. Maternal age, educational status, place of most recent delivery, residents and danger sign causes problem or death to the mother were independently associated with awareness of women about danger sign of pregnancy.

Conclusion: Three fourth of study subjects didn't have awareness about DSP. Maternal age, maternal education, place of most recent delivery, residents and danger sign causes problem or death to the mother were independently associated with awareness of women about danger sign of pregnancy. Thus, provision of information, education and communication targeting women, family and the general community on danger signs of pregnancy and associated factors was recommended.

Keywords: Level of awareness; Danger signs of pregnancy

Abbreviations DSP: Danger Sign of Pregnancy; EDHS: Ethiopian Demographic Health Survey; FMoH: Federal Ministry of Health; MMR: Maternal Mortality Rate; GA: Gestational Age; SSA; Sub Saharan Africa; WHO: World Health Organization

\section{Introduction}

Globally MMR stood at 216 which is 303000 estimated deaths and approximately 99\% (302 000) of this deaths occurs in developing regions. The main burden of these deaths is shouldered by SSA and
South Asia. Both together bear $87 \%$ of which roughly $66 \%$ (201000) or 546 per 100,000 live births occurring in the SSA alone. In Ethiopia MMR estimated 412 per 100,000 live births which accounted for $21 \%$ of all deaths and the highest in the world [1-3].

Childbearing is experienced not as the joyful event as it should be [4]. Since every pregnant woman faces the risk of sudden unpredictable complications that could end in death or injury to herself or to her infant [5]. In developing world for every woman who dies as a result of pregnancy and child birth over 30 million women suffer each year from serious obstetric complications, injuries, infections because of inadequate or inappropriate care during 
Citation: Abdurashid N, Ishaq N, Ayele K, Ashenafi N (2018) Level of Awareness on Danger Signs During Pregnancy and Associated Factors, among Pregnant Mothers, Dire Dawa Administrative Public Health Facilities, Eastern Ethiopia. Clinics Mother Child Health 15: 290. doi: $10.4172 / 2090-7214.1000290$

Page 2 of 12

pregnancy, delivery and post natal [4]. Obstetrics related complications are among the greatest killers of women of reproductive age in developing countries. Especially in low-resource countries, like Ethiopia, childbirth is often associated with unpredictable lifethreatening obstetric complications that lead to maternal and neonatal morbidity and mortality [6-12].

Despite various safe motherhood initiatives and interventions in East Africa, studies in Tanzania, Ethiopia, Burkina Faso and Uganda have shown that even within the last five years awareness of obstetric danger signs during pregnancy, delivery and postpartum were still low especially in rural populations [13-15]. Insufficient knowledge about danger signs of pregnancy among women, families, and birth attendants in developing world is one of the major contributing factors for maternal deaths [16] these death can be reduced by empowering women with knowledge on obstetrics danger signs, promote appropriate health seeking attitude and counselling on the obstetric danger signs of its unpredictable complications and its appropriate managements are crucial [17]. So that, women are expected to receive health education about pregnancy including outcomes, danger signs during pregnancy, nutrition and family planning and other services when they attend clinic for ANC [7].

FMoH of Ethiopia in 2015, emphasis was given to set goal of reproductive health program strategy to reduce maternal mortality ratio from 412 to 199 per 100,000 live births by 2020 through ANC, birth plan package and its main components which includes key elements, recognition of danger signs [2,5] to ensure these $80 \%$ of all families should recognize at least three danger signs associated with pregnancy related complications [18] because only one in five was informed of signs of pregnancy complications [19]. Since $62 \%$ of women receive ANC from a skilled provider at least once for their last birth [2] besides the risk factors for pregnancy complications which are listed on ANC card not enough to tell to client and hence for those pregnant women who are able to read will still lack the information [20].

Lack of awareness on the significance of symptoms of danger signs of obstetric complications is one of the reasons of failure of women to identify and to reach health care facilities and to seek appropriate emergency care before severe forms of obstetric complications arise in which both mother and baby become at risk of dying from it [19] so that assessment of women's awareness of obstetric danger signs and associated factors contributes to their awareness [16]. Accordingly, raising awareness of pregnant women on the danger signs would improve early detection of problems and reduces the delay in deciding to seek obstetric care [18]. Because knowing this warning sign is important for both women and health care providers to rule out serious complications and initiate treatment immediately [16]. Thus, efforts should be done to increase awareness of obstetric danger signs [20]. Since little is known about the current level of knowledge and the influencing factors about danger signs of pregnancy in Ethiopia as well in study area. This study provides information and fills the knowledge gap on danger signs of pregnancy and identifies risk factors among ANC attendants.

\section{Methods and Materials}

The study was conducted in Diredawa administrative town, eastern Ethiopia located $515 \mathrm{~km}$ away from the capital city of Addis Ababa. According to 2009 census of Diredawa regional health bureau; the total population of Diredawa city administrative was 466,000 . The city has one referral and one primary hospital, 15 health centres which are 7 in rural and 8 in urban and 32 health posts, 3 private hospitals, 2 clinics and 32 mid-level clinics.

\section{Study design and period}

Facility based cross sectional study design was used from Jan 1 to March 30/2017

\section{Source population}

All women attended ANC in selected health centers of Diredawa city administration.

\section{Study population}

All randomly selected pregnant women who were attended ANC in selected health centers.

\section{Sample size determination and sampling technique}

Sample size determination: The sample size for the study was determined by using two-population proportion based on the following assumption.

\section{$\mathrm{P} 2=50 \%$}

$\mathrm{OR}=2$

$\mathrm{CL}=99 \%$

\section{POWER $=80 \%$}

\section{$\mathrm{r}=1: 1$}

Accordingly sample size for cross sectional study was calculated by stat calc program of Epi-info 3.5.3 the final result obtained was 456 (228 each for urban and rural). Therefore, the minimum sample size calculated was 456 (228 each for urban and rural). A contingency of $10 \%$ which is 46 used for non-response rate. The required total sample size became 502 .

Sampling technique and procedure: From the total health centres, six were selected by simple random sampling technique, three from each resident. These facilities were given service for 3575 pregnant mothers in the past one year of which 1500 in rural (274 in Melkajebdu, 281 in Wahil and 945 in Biyoawale) and 2075 in urban (1389 in Legehare, 349 in Gendegerada and 337 Adisketema). The number of pregnant mothers in Biyoawale health centres was estimated higher in rural and Legehare health centres in urban. The total sample size of the study was allocated proportionally for the selected health centres both in urban and rural to avoid selection bias and to minimize disproportion between them. The proportion sample size of pregnant mothers were calculated by multiplying total sample size (502) and number of ANC attendants of each health centre and then divided by the total population size (3575). So that totally 211 pregnant mothers was allocated for rural health centres which was 39 from Melkajebdu, 39 from Wahil and 133 from Biyoawale as well, a of total of 291 study subjects were allocated for urban health centres which was 195 from Legehare, 49 from Gendegerada and 47 from Adis-ketema. A systematic random sampling technique was used to select study subjects in each health facilities. The first mother interviewed from each health centres was chosen by lottery methods and then next study subject was selected by calculating sampling interval of $\left(\mathrm{K}^{\text {th }}\right)=\mathrm{N} / \mathrm{n}$ for each health centres. 
Citation: Abdurashid N, Ishaq N, Ayele K, Ashenafi N (2018) Level of Awareness on Danger Signs During Pregnancy and Associated Factors, among Pregnant Mothers, Dire Dawa Administrative Public Health Facilities, Eastern Ethiopia. Clinics Mother Child Health 15: 290. doi: $10.4172 / 2090-7214.1000290$

Page 3 of 12

\section{Data collection method}

Pretested structured interviewer administered questionnaire, which was first prepared in English and translated to local language was employed to obtain information on socio-demographic, obstetric history, and knowledge of women about danger signs of pregnancy. Data collectors were diploma graduated midwives with at least 2 years of working experience trained for one day to conduct the interview. The subjects were first explained about the purpose of the study. It was also made clear that, the results of the tests will neither have bearing on their pregnancy nor on personal life. Rapport was established with the subjects before the administration of the tests. The questionnaires were administered in the above mentioned order.

\section{Data analysis}

Prior to analysis, data cleaning, coding, checking for normality, completeness was done, then data was entered in to SPSS version 20.0. Descriptive statistics was computed to determine the level of awareness. Level of awareness of danger sign of pregnancy was assessed by 16 variables that measures the extent of pregnant women mentioned the types of danger sign with yes or no response. If they respond three or more of awareness measurements were considered as having good level of awareness and less than three was considered as having poor level of awareness. Bivariate analysis was carried out between the dependent and independent variables to determine their association. Binary logistic regression analysis was made to obtain odds ratio and the $\mathrm{CI}$ for statistical association variables. And multivariable logistic regression analysis was carried out to assess strength of statistical association (AOR) of level of awareness of danger sign of pregnancy with socio-demographic, ANC and obstetrics history related variables. Variables significant in Bivariate analysis at $\mathrm{p}<0.05$ and $\mathrm{p}<0.2$ were taken and entered into multivariate analysis. The strength of statistical association was measured by AOR at $95 \%$ CI. Statistical significance is declared at $\mathrm{P}<0.05$.

\section{Outcome measure}

The outcome measure of the study was client's awareness of the danger signs of pregnancy and it was assessed by recalling three or more of the sixteen danger signs of pregnancy spontaneously would be considered having good awareness and had poor awareness if mentioned less than three signs. The items included vaginal bleeding, reduced marked change in fetal movement, swollen face and leg, blurred vision, sever persistent abdominal pain, PROM, loss of consciousness, difficulty of breathing, high grade fever, weakness to get out of bed, chills, persistent vomiting, sever recurrent frontal head ache, awareness of high $\mathrm{B} / \mathrm{P}$, dysuria, oliguria/anuria.

\section{Result}

The data was compiled from 502 ANC attending mother at different health centres. For the ease of understanding the main results are presented under the sub headings as follows:

\section{Socio-demographic characteristics}

Table 1 shows the socio-demographic characteristics of the study subjects observed that, the mean age of the respondents was 25.13 (SD \pm 5.803 , age range of $15-41)$. The majority of mothers $172(34.3 \%)$ were in age group between $25-29$ years, 491 (97.8\%) were married, 330 (65.7\%) were house wife, $443(88.2 \%)$ were Muslim, 359 (71.5\%) were Oromo in ethnicity, 315 (62.7\%) born in rural, 311 (62\%) were urban residents, 255 (50.3\%) were illiterate, 255 (50.3\%) had less than three family size, 415 (82.5\%) were traveling less than $1 \mathrm{~h}$ to health facility, only $293(58.4 \%)$ were disclosed about their monthly income and of them 248 (84.6\%) had monthly income more than 1000 birr.

\begin{tabular}{|c|c|c|c|}
\hline \multicolumn{2}{|c|}{ Demographic Variable } & \multirow{2}{*}{$\begin{array}{l}(n=502) \\
84\end{array}$} & \multirow{2}{*}{$\begin{array}{l}\text { Percent } \\
16.7\end{array}$} \\
\hline Maternal age & $15-19$ & & \\
\hline & $20-24$ & 152 & 30.3 \\
\hline & $25-29$ & 172 & 34.3 \\
\hline & $\geq 30$ & 94 & 18.8 \\
\hline \multirow[t]{4}{*}{ Marital status } & Separated & 5 & 1.0 \\
\hline & Married & 491 & 97.8 \\
\hline & Widowed & 4 & 0.8 \\
\hline & Divorced & 2 & 0.4 \\
\hline \multirow[t]{6}{*}{ Occupation } & Gov't & 29 & 5.8 \\
\hline & Housewife & 330 & 65.7 \\
\hline & Out of work & 18 & 3.6 \\
\hline & Farmer & 51 & 10.2 \\
\hline & Daily labourer & 28 & 5.6 \\
\hline & NGOs & 5 & 1.0 \\
\hline
\end{tabular}


Citation: Abdurashid N, Ishaq N, Ayele K, Ashenafi N (2018) Level of Awareness on Danger Signs During Pregnancy and Associated Factors, among Pregnant Mothers, Dire Dawa Administrative Public Health Facilities, Eastern Ethiopia. Clinics Mother Child Health 15: 290. doi: $10.4172 / 2090-7214.1000290$

Page 4 of 12

\begin{tabular}{|c|c|c|c|}
\hline & Merchant & 41 & 8.2 \\
\hline \multirow[t]{5}{*}{ Ethnicity } & Harari & 8 & 1.6 \\
\hline & Oromo & 359 & 71.5 \\
\hline & Amhara & 43 & 8.6 \\
\hline & Gurage & 21 & 4.2 \\
\hline & Somali & 71 & 14.1 \\
\hline \multirow[t]{4}{*}{ Religion } & Muslim & 443 & 88.2 \\
\hline & Orthodox & 49 & 9.8 \\
\hline & Protestant & 4 & 0.8 \\
\hline & Catholic & 6 & 1.2 \\
\hline \multirow[t]{5}{*}{ Educational level } & Not read and write & 222 & 44.2 \\
\hline & Read and write only & 112 & 22.3 \\
\hline & Primary & 113 & 22.5 \\
\hline & Secondary & 35 & 7.0 \\
\hline & College/University & 20 & 4.0 \\
\hline \multirow[t]{2}{*}{ Place of birth } & Urban & 187 & 37.3 \\
\hline & Rural & 315 & 62.7 \\
\hline \multirow[t]{2}{*}{ Residence } & Urban & 291 & 58 \\
\hline & Rural & 211 & 42 \\
\hline \multirow[t]{2}{*}{ Travel time to health facility } & $<1 \mathrm{~h}$ & 415 & 82.7 \\
\hline & $\geq 1 \mathrm{~h}$ & 87 & 17.3 \\
\hline \multirow[t]{4}{*}{ Family size } & $<3$ & 255 & 50.8 \\
\hline & $4-5$ & 159 & 31.7 \\
\hline & $6-7$ & 60 & 12.0 \\
\hline & $\geq 8$ & 28 & 5.6 \\
\hline \multirow[t]{4}{*}{ Monthly income } & $100-300$ & 7 & 2.4 \\
\hline & $301-500$ & 10 & 3.4 \\
\hline & $501-1000$ & 28 & 9.6 \\
\hline & $>1000$ & 248 & 84.6 \\
\hline
\end{tabular}

Table 1: Socio-demographic characteristics of ANC Attendant in health centers, in Diredawa, Ethiopia, 2017.

\section{Obstetrics history}

About 359 (71.5\%) said that they wanted their pregnancy. 166 (33.1\%) and $48(9.4 \%)$ were pregnancy less than 3 months and greater or equal to 9 months respectively, $142(28.3 \%)$ and 129 (25.7\%) were prim-gravid and become pregnant for the more than three times respectively, 150 (29.9\%) and $161(32.1 \%)$ were not given birth before and gave birth once respectively. 296 (59\%) had normal spontaneous vaginal delivery and $23(4.6 \%)$ were instrumental delivery. The majority $403(80.3 \%)$ had no history of abortion. 242 (48.2\%) were given birth of their most recent child in health centres and $60(12 \%)$ were gave their first birth at age of 15 years. 352 (70.1\%) and 24 (4.8\%) were visited ANC clinic two time and more than four times respectively. $335(66.7 \%)$ and $24(4.8 \%)$ were booked at gestational age less or equal to four months and at nine month respectively. Regarding risk of pregnancy 67 (13.3\%) study subjects had previous risks. About 449 (89.4\%) and 23 (4.6\%) were not had chronic medical illness and asthmatic respectively. 59 (11.8\%) were developed danger sign in present pregnancy. Regarding laboratory blood examinations 206 (41\%) were blood group "O" and $444(89.4 \%)$ positive Rh-factor and $164(32.7 \%)$ had haemoglobin of 12 to $16 \mathrm{gm} / \mathrm{dl}$. The mean weight of 
Citation: Abdurashid N, Ishaq N, Ayele K, Ashenafi N (2018) Level of Awareness on Danger Signs During Pregnancy and Associated Factors, among Pregnant Mothers, Dire Dawa Administrative Public Health Facilities, Eastern Ethiopia. Clinics Mother Child Health 15: 290. doi: $10.4172 / 2090-7214.1000290$

Page 5 of 12

participants was 57.14 (SD+7.069, weight range of 44-89). Regarding their babies' health, it is found that only 28 (5.6\%) of the study subjects having babies with health problems. These problems are congenital malformations $16(3.2 \%)$, small for date babies $7(1.4 \%)$ and macrosomic babies 5 (1\%) (Table 2).

\begin{tabular}{|c|c|c|c|}
\hline \multicolumn{2}{|l|}{ Obstetrics Variable } & \multirow{2}{*}{$\begin{array}{l}\text { Frequency } \\
62\end{array}$} & \multirow{2}{*}{$\begin{array}{l}\text { Percent } \\
12.4\end{array}$} \\
\hline & Not at all & & \\
\hline Pregnancy intended & Mistimed & 81 & 18.1 \\
\hline & Wanted & 359 & 71.5 \\
\hline \multirow{4}{*}{ Months of pregnancy } & $\leq 3$ months & 166 & 33.1 \\
\hline & 4-6 months & 146 & 29.1 \\
\hline & 7-8 months & 143 & 28.5 \\
\hline & $\geq 9$ months & 47 & 9.4 \\
\hline \multirow{5}{*}{ Place of most recent child delivery } & Home & 35 & 7 \\
\hline & Gov't hospital & 30 & 6 \\
\hline & Health centre & 242 & 48.2 \\
\hline & Private hospital & 53 & 10.6 \\
\hline & Primigravid & 142 & 28.3 \\
\hline \multirow{4}{*}{ Type of delivery } & Normal/SVD & 296 & 59 \\
\hline & Cesarian section & 41 & 8.2 \\
\hline & Instrumental & 23 & 4.6 \\
\hline & Primigravid & 142 & 28.3 \\
\hline \multirow{4}{*}{ Age at first birth } & $\leq 15$ years & 60 & 12 \\
\hline & $16-20$ years & 253 & 50.4 \\
\hline & $\geq 21$ years & 47 & 9.4 \\
\hline & Primigravid & 142 & 28.3 \\
\hline \multirow{4}{*}{ Gravida } & Once & 142 & 28.3 \\
\hline & Twice & 121 & 24.1 \\
\hline & 3 times & 110 & 21.9 \\
\hline & $>3$ & 129 & 25.7 \\
\hline \multirow{4}{*}{ Number of abortion } & None & 403 & 80.3 \\
\hline & Once & 88 & 17.5 \\
\hline & Twice & 9 & 1.8 \\
\hline & Triple & 2 & 0.4 \\
\hline \multirow{5}{*}{ Parity } & None & 150 & 29.9 \\
\hline & 1 & 161 & 32.1 \\
\hline & 2 & 85 & 16.9 \\
\hline & 3 & 35 & 7 \\
\hline & $4+$ & 71 & 14.1 \\
\hline
\end{tabular}


Citation: Abdurashid N, Ishaq N, Ayele K, Ashenafi N (2018) Level of Awareness on Danger Signs During Pregnancy and Associated Factors, among Pregnant Mothers, Dire Dawa Administrative Public Health Facilities, Eastern Ethiopia. Clinics Mother Child Health 15: 290. doi: $10.4172 / 2090-7214.1000290$

Page 6 of 12

\begin{tabular}{|c|c|c|c|}
\hline \multirow{3}{*}{ Previous risk of pregnancy } & Yes & 67 & 13.3 \\
\hline & No & 293 & 58.4 \\
\hline & Primigravida & 142 & 28.3 \\
\hline \multirow{3}{*}{ Having babies with problem } & Yes & 28 & 5.6 \\
\hline & No & 332 & 66.1 \\
\hline & Primigravida & 142 & 28.3 \\
\hline \multirow{5}{*}{ Chronic medical illness } & Asthma & 23 & 4.6 \\
\hline & Diabetics & 22 & 4.4 \\
\hline & HTN & 7 & 1.4 \\
\hline & Heart disease & 1 & 0.2 \\
\hline & No & 449 & 89.4 \\
\hline \multirow{4}{*}{ Months booked } & $\leq 4^{\text {th }}$ month & 335 & 66.7 \\
\hline & $5-6$ months & 78 & 15.5 \\
\hline & $7-8$ months & 65 & 12.9 \\
\hline & 9 months & 24 & 4.8 \\
\hline \multirow{3}{*}{ Type of problems baby had } & Congenital malformation & 16 & 3.2 \\
\hline & Small for date & 7 & 1.4 \\
\hline & Macrosomic baby & 5 & 1 \\
\hline \multirow{4}{*}{ Number of ANC visit } & $\leq 2$ & 352 & 70.1 \\
\hline & 3 & 89 & 17.7 \\
\hline & 4 & 37 & 7.4 \\
\hline & $>4$ & 24 & 4.8 \\
\hline \multirow{2}{*}{ Developed danger sign in present pregnancy } & Yes & 59 & 11.8 \\
\hline & No & 443 & 88.2 \\
\hline \multirow{4}{*}{ Blood group } & A & 152 & 30.3 \\
\hline & B & 104 & 20.7 \\
\hline & $A B$ & 40 & 8 \\
\hline & $\mathrm{O}$ & 206 & 41 \\
\hline \multirow{2}{*}{ Rh factors } & Negative & 53 & 10.6 \\
\hline & Positive & 449 & 89.4 \\
\hline \multirow{4}{*}{ Haemoglobin } & $<7 \mathrm{gm} / \mathrm{dl}$ & 15 & 3 \\
\hline & $7-9 \mathrm{gm} / \mathrm{dl}$ & 54 & 10.8 \\
\hline & $10-11 \mathrm{gm} / \mathrm{dl}$ & 269 & 53.6 \\
\hline & $12-16 \mathrm{gm} / \mathrm{dl}$ & 164 & 32.7 \\
\hline
\end{tabular}

Table 2: Obstetrics history of ANC attendant in health centres, in Diredawa, eastern Ethiopia, 2017. 
Citation: Abdurashid N, Ishaq N, Ayele K, Ashenafi N (2018) Level of Awareness on Danger Signs During Pregnancy and Associated Factors, among Pregnant Mothers, Dire Dawa Administrative Public Health Facilities, Eastern Ethiopia. Clinics Mother Child Health 15: 290. doi: $10.4172 / 2090-7214.1000290$

Page 7 of 12

\section{Knowledge and counselling assessment}

About 489 (97.4\%) of study subjects were given health talk during their ANC visit but $439(87.5 \%)$ and $63(12.5 \%)$ were considered adequate and inadequate respectively. $464(92.4 \%)$ were informed about obstetrics danger sign. 241 (48\%), 206 (41\%), 195 (38.8\%) and $99(19.7 \%)$ respondents were obtained information about obstetrics danger sign from health professionals, friends, relatives and media respectively. $407(81.1 \%)$ and $343(68.3 \%)$ of respondents were thought danger sign may cause problems or death for the mother and the foetus respectively. 66 (13.5\%) and 101 (20.1\%) of respondents were didn't know that danger sign causes problems or death for the mother and foetus respectively (Table 3).

\begin{tabular}{|c|c|c|c|}
\hline \multicolumn{2}{|l|}{ Variable } & \multirow{2}{*}{$\begin{array}{l}\text { Frequency } \\
489\end{array}$} & \multirow{2}{*}{$\begin{array}{l}\text { Percent } \\
97.4\end{array}$} \\
\hline Health talks given during ANC & Yes & & \\
\hline & No & 13 & 2.6 \\
\hline Health talks received considered adequate & Adequate & 439 & 87.5 \\
\hline \multirow{3}{*}{ Informed about obstetrics danger signs } & Inadequate & 63 & 12.5 \\
\hline & Yes & 464 & 92.4 \\
\hline & No & 38 & 7.6 \\
\hline \multirow[t]{12}{*}{ What is other source of information about DSP? } & \multicolumn{3}{|l|}{ From media } \\
\hline & Yes & 99 & 19.7 \\
\hline & No & 403 & 80.3 \\
\hline & \multicolumn{2}{|l|}{ From friends } & \\
\hline & Yes & 206 & 41 \\
\hline & No & 296 & 59 \\
\hline & \multicolumn{2}{|c|}{ From relatives } & \\
\hline & Yes & 195 & 38.8 \\
\hline & No & 307 & 61.2 \\
\hline & \multicolumn{2}{|c|}{ From health professional } & \\
\hline & Yes & 241 & 48 \\
\hline & No & 261 & 52 \\
\hline \multirow[t]{3}{*}{ Do you think that danger sign may cause problems/death for the mother? } & Yes & 407 & 81.1 \\
\hline & No & 29 & 5.8 \\
\hline & I don't know & 66 & 13.1 \\
\hline \multirow[t]{3}{*}{ Do you think that danger sign may cause problems/death for the fetus } & Yes & 343 & 68.3 \\
\hline & No & 58 & 11.6 \\
\hline & I don't know & 101 & 20.1 \\
\hline
\end{tabular}

Table 3: Knowledge and counseling assessment of ANC attendant in health centers, in Diredawa, Ethiopia.

\section{Knowledge on danger signs during pregnancy}

Respondents when asked about danger signs that occur during pregnancy, most commonly mentioned were vaginal bleeding by 373 (74.3\%), edema of face and hand/leg by 135 (26.9\%), blurred vision $134(26.7 \%)$, reducing fetal movement by $116(23.1 \%)$ early rupture of membrane 77 (15.3\%), foul vaginal discharge 73 (14.5), severe abdominal pain 65 (12.9\%) and other signs mentioned were less than $10 \%$ (difficulty of breathing, high fever, weakness, chills, severe frontal head ache, high $\mathrm{B} / \mathrm{P}$ ) as well dysuria, and anuria were not mentioned at all (Table 4).

\begin{tabular}{|l|l|l|}
\hline Variable & Yes n (\%) & No $\mathbf{n}(\%)$ \\
\hline Vaginal bleeding & $373(74.3 \%)$ & $129(25.7 \%)$ \\
\hline Marked reduction in foetal movement & $16(23.1 \%)$ & $386(76.9 \%)$ \\
\hline Swollen face and leg & $135(26.9 \%)$ & $367(73.1 \%)$ \\
\hline
\end{tabular}


Citation: Abdurashid N, Ishaq N, Ayele K, Ashenafi N (2018) Level of Awareness on Danger Signs During Pregnancy and Associated Factors, among Pregnant Mothers, Dire Dawa Administrative Public Health Facilities, Eastern Ethiopia. Clinics Mother Child Health 15: 290. doi: $10.4172 / 2090-7214.1000290$

Page 8 of 12

\begin{tabular}{|l|l|l|}
\hline Blurred vision & $134(26.7 \%)$ & $368(73.3 \%)$ \\
\hline Persistent abdominal pain & $65(12.9 \%)$ & $437(87.1 \%)$ \\
\hline PROM & $77(15.3 \%)$ & $425(84.7 \%)$ \\
\hline Loss of consciousness & $25(5.0 \%)$ & $477(95.0 \%)$ \\
\hline Difficulty of breathing & $9(1.8 \%)$ & $493(98.2 \%)$ \\
\hline High grade fever & $39(7.8 \%)$ & $463(92.2 \%)$ \\
\hline Weakness to get out of bed & $31(6.2 \%)$ & $471(93.8 \%)$ \\
\hline Chills & $12(2.4 \%)$ & $490(97.6 \%)$ \\
\hline Persistent vomiting & $73(14.5 \%)$ & $429(85.5 \%)$ \\
\hline Recurrent frontal head ache & $21(4.2 \%)$ & $481(95.8 \%)$ \\
\hline Awareness of high B/P & $32(6.4 \%)$ & $470(93.6 \%)$ \\
\hline Dysuria & $0(0 \%)$ & $502(100 \%)$ \\
\hline Oliguria/anuria & $0(0 \%)$ & $502(100 \%)$ \\
\hline
\end{tabular}

Table 4: Danger sign that occurs during pregnancy.

\section{Level of awareness of danger sign of pregnancy}

From the total 16 questions of danger signs of pregnancy 75 (14.9\%) didn't mention any of the signs that occur during pregnancy while 1 respondent was answered $10(0.2 \%)$ out of total questions. Ranges 0 -10, over all mean score is $2.27(\mathrm{SD} \pm 1.71)$ and about $121(24.1 \%)$ of pregnant mothers had good awareness and 381 (75.9\%) had low awareness of danger sign of pregnancy (Table 5).

\begin{tabular}{|l|l|l|}
\hline Variable & Frequency & Percent \\
\hline Poor awareness & 381 & $75.9 \%$ \\
\hline Good awareness & 121 & $24.1 \%$ \\
\hline
\end{tabular}

Table 5: Level of awareness of danger sign of pregnancy.

\section{Association between dependent and independent variables}

Dependant and independent variables were cross tabulated with each maternal characteristics related factors and level of awareness of danger sign of pregnancy. The relation between level of awareness of the study subjects and their general characteristics (Tables 5 and 6).

There were no significant associations observed between DSP and marital status, occupation, ethnicity, place of birth, travel time to

health centre, family size and monthly income with good awareness of DSP.

However, bivariate logistic regression analysis showed that maternal age between $20-24$ years were $0.31 \%$ times more likely and age $\geq 30$ years were $0.54 \%$ times more likely to have good awareness of danger sign of pregnancy than age between 15 to 19 years. Besides; multivariate logistic regression showed that statistical significant association at $(\mathrm{p}<0.05)$ observed between age 20-24 years were 3.11 times more likely [AOR $(95 \% \mathrm{CI})=3.114(1.431,6.778$ and age $\geq 30$ years 3.91 times more likely $[\mathrm{AOR}(95 \% \mathrm{CI})=3.914(3.405,10.904)]$ to have good awareness of danger sign of pregnancy than age between $15-19$ years.

There was no significance association were observed in educational level and danger sign of pregnancy. But statistical significant association $(\mathrm{p}<0.05)$ were observed in primary educated 2.05 times more likely [AOR $(95 \% \mathrm{CI})=2.054(1.054,4.003)]$ secondary educated were 3.12 time more likely $[\mathrm{AOR}(95 \% \mathrm{CI})=3.107(1.201,8.036)]$ and college/university graduates were 3.15 times more likely [AOR ( $95 \%$ $C I)=3.146(1.053,9.402)]$ to have good awareness of danger signs of pregnancy than those who can't read and write.

There were statistical associations observed between DSP and residents of study subjects. Bivariate logistic regression analysis showed that rural residents were 1.72 time more likely and in multivariate logistic regression rural habitants were 2.79 times more likely [AOR $(95 \% \mathrm{CI})=2.793(1.686,4.626)]$ to have good awareness than those from urban residents.

There were no significant associations observed between DSP and pregnancy intendedness, monthly booked, age at first birth, number of ANC, gravida, abortion, previous risk of pregnancy, having baby with problem, chronic medical illness, place of previous delivery, type of delivery, health talk given during pregnancy, adequacy of health talk, but there was significant association were observed that place of most recent delivery, parity, informed about DSP, knowing that DSP causes problem or death to the mother and/or baby with good awareness of DSP. But statistical significant association $(p<0.05)$ were observed in place of most recent delivery and knowing that DSP causes problem or death to the mother. Those mothers who gave birth in health centre 3.41 time more likely [AOR $(95 \% \mathrm{CI})=3.414(1.078,10.814)]$ and those in private hospital were 5.52 times more likely [AOR $(95 \% \mathrm{CI})=5.514$ $(1.551,19.601)]$ to have good awareness of danger sign of pregnancy than home birth. Mothers who were unaware of DSP causes problem or death to themselves were $0.41 \%$ more likely [AOR $(95 \% \mathrm{CI})=0.409$ $(0.182,0.922)]$ to have poor awareness than those who knows (Table $6)$.

\begin{tabular}{|l|l|l|l|l|l|}
\hline Characteristics & n=502 & P & COR at 95\% Cl & P & AOR at 95\% Cl \\
\hline Age of mother & $84(16.7 \%)$ & & 1 & & 1 \\
\hline $15-19$ & $152(30.3 \%)$ & 0.002 & $0.306(0.142,0.659)^{*}$ & 0.004 & $3.114(1.431,6.778)^{* *}$ \\
\hline $20-24$ & $172(34.3 \%)$ & 0.436 & $0.802(0.460,1.398)$ & 0.120 & $1.993(0.835,4.756)$ \\
\hline $25-29$ & $94(18.8 \%)$ & 0.032 & $0.538(0.306,0.947)^{*}$ & 0.009 & $3.914(3.405,0.904)^{* *}$ \\
\hline$\geq 30$ &
\end{tabular}


Citation: Abdurashid N, Ishaq N, Ayele K, Ashenafi N (2018) Level of Awareness on Danger Signs During Pregnancy and Associated Factors, among Pregnant Mothers, Dire Dawa Administrative Public Health Facilities, Eastern Ethiopia. Clinics Mother Child Health 15: 290. doi: $10.4172 / 2090-7214.1000290$

Page 9 of 12

\begin{tabular}{|c|c|c|c|c|c|}
\hline \multicolumn{6}{|l|}{ Education level } \\
\hline Not read and write & $222(44.2 \%)$ & & 1 & & 1 \\
\hline Read and write only & $112(22.3 \%)$ & 0.675 & $1.121(0.656,1.918)$ & 0.116 & $1.630(0.886,3.001)$ \\
\hline Primary & $113(22.5 \%)$ & 0.578 & $1.163(0.683,1.980)$ & 0.035 & $2.054(1.054,4.003)^{* *}$ \\
\hline Secondary & $35(7 \%)$ & 0.397 & $1.412(0.635,3.140)$ & 0.019 & $3.107(1.201,8.036)^{\star *}$ \\
\hline College/University & $20(4 \%)$ & 0.195 & $1.901(0.719,5.025)$ & 0.040 & $3.146(1.053,9.402)^{* *}$ \\
\hline \multicolumn{6}{|l|}{ Residents } \\
\hline Urban & $311(62 \%)$ & & 1 & & 1 \\
\hline Rural & $191(38 \%)$ & 0.011 & $1.717(1.134,2.598)^{*}$ & 0.000 & $2.793(1.686,4.626)^{* *}$ \\
\hline \multicolumn{6}{|c|}{ Place of most recent delivery } \\
\hline Home & $29(5.8 \%)$ & & 1 & & 1 \\
\hline Gov't hospital & $330(65.7 \%)$ & 0.124 & $2.818(0.754,10.536)$ & 0.064 & $3.786(0.927,15.460)$ \\
\hline Health centre & $18(3.6 \%)$ & 0.082 & $2.612(0.886,7.699)$ & 0.037 & $3.414(1.078,10.814)^{\star *}$ \\
\hline Private hospital & $51(10.2 \%)$ & 0.022 & $3.986(1.217,13.054)^{*}$ & 0.008 & $5.514(1.551,19.601)^{* *}$ \\
\hline Primigravid & $28(5.6 \%)$ & 0.200 & $2.076(0.680,6.340)$ & 0.456 & $2.096(0.300,14.650)$ \\
\hline \multicolumn{6}{|c|}{ Do you think that danger sign causes problem or death to the mother } \\
\hline Yes & $407(81.1)$ & & 1 & & 1 \\
\hline No & $29(5.8 \%)$ & 0.133 & $0.437(0.149,1.286)$ & 0.231 & $0.502(0.162,1.550)$ \\
\hline I don't know & $66(13.1 \%)$ & 0.013 & $0.377(0.174,0.815)^{*}$ & 0.031 & $0.409(0.182,0.922)^{* *}$ \\
\hline
\end{tabular}

NB: These variables are from the total variables statistical significant while cross tabulation done $(p<0.05)($ Age of mother, educational status, residents, place of most recent delivery and danger sign causes problem or death to the mother).

Table 6: Bivariate and multivariate logistic regression model showing predictors of danger sign of pregnancy among ANC attendants in public health facilities in Diredawa administration from Jan 1 to March 30/2017.

\section{Discussion}

In this study $92.4 \%$ study subjects were informed about the danger signs related to pregnancy. This is in agreement with study done in Nigeria Southeast [21] Ibadan [22], and higher than study done in northern part of Ethiopia, Mekelle city [23] Tsegedi district Tigray [4] but lower than Mbarara district Uganda [15].

This difference might be due to the city administration, regional health bureau, stake holders, health professionals working together and implemented relevant strategies to improve the access and utilization of the health care information in order to minimize maternal mortality rate.

In our study, $74.3 \%$ study subjects mentioned vaginal bleeding which is higher than study done in different part of Ethiopia Tsegedi district 49.1\% [4] Debark town north west 66.8\% [10] Adigrat $10.9 \%$ [14], Debra Birhan town 45.4\% [16] Aleta Wondo, Southern 45.9\% [18] Mekelle city Tigray 68.5\% [24] Debaytilatgin district 53.7\% [25] and other part of African countries like in Tanzania 50\% [13] Mbarara district Uganda 49.2\% [15] Burkina Faso 39.4\% [26], Guatemala 31.0\% [27], Rewa district of Madhya Pradesh [28], Southeast Nigeria 67\% [21] Lagos, Nigeria 48.4\% [29], Malawi 39\% [30] Uganda 67.4\% [31] Burkina Faso 24.8\%, Ghana 29.3\%, Tanzania 57.6\% [32] Tanzania 19\%
[33] but lower than study done in Dar-es-salaam, Tanzania 81.2\% [20] BRD Medical College, Gorakhpur, India 90.5\% [34].

This difference might be due to socio-cultural difference and difference in the implementation of relevant health intervention programs. This could also be attributable to the time gap that there could be improved in access and utilization of the health care information being provided.

In this study, $24.1 \%$ of study subjects had good awareness of danger signs of pregnancy. This is consistent with study done in Arba Minch, Ethiopia 24.1\% [35] Alexandria, Egypt 26\% [11], but higher than Mbarara district Uganda 19\% [15] Jordan 15.2\% [36] Uganda 20\% [31] South Africa 16\% [37] Tanzania 14.8\% [33] but lower than study done in other part of Ethiopia, Tsegedi distric 58.8\% [4] Debark town north west 47\% [10], Debra Birhan town 38.6\% [16] AletaWondo 30.4\% [18] East Gojjam Zone 55.1\% [38] Mekelle city Tigray $82.5 \%$ [24] Debaytilatgin District 56.8\% [39] in South Africa, Kwazulu-Natal, province [40]. North West Province 72.6\% [37] Dar-es-salaam, Tanzania 31\% [20] Southeast Nigeria 53.7\% [30] in India Narayana Medical college hospital 49.9\% [41] Salem, Tamil Nadu 34\% [9], India $79.2 \%[25]$. 
Citation: Abdurashid N, Ishaq N, Ayele K, Ashenafi N (2018) Level of Awareness on Danger Signs During Pregnancy and Associated Factors, among Pregnant Mothers, Dire Dawa Administrative Public Health Facilities, Eastern Ethiopia. Clinics Mother Child Health 15: 290. doi: $10.4172 / 2090-7214.1000290$

Page 10 of 12

Generally, the awareness level is much lower than most research done in other part of the world. This difference might be due to the method used to inform the mothers about danger signs of pregnancy is inadequate or one way communication which may not consider clients background.

In our study $14.9 \%$ of the respondents were unable to mention any danger sign of pregnancy, which is lower than the findings from Tsegedi district 35.1\% [4] Aleta Wondo, Ethiopia 39.0\% [18]. Southeast Nigeria 17\% [21] Burkina Faso 58.2\%, Ghana, 21.7\% and in Tanzania $30.0 \%$ [32] South Africa 39\% [37].

This difference may be due to better methods were used to inform ANC attendants mothers about DSP.

In this study maternal age was one factor that has been indicated as predictors of awareness of danger signs of pregnancy. When maternal age increases level of awareness of danger sign of pregnancy became good.

This finding is consistent with study done in Tsegedi district [4] Debark town north west Ethiopia 66.8\% [10] Egypt [11] and Tanzania [13] Dar-es-salaam, Tanzania [20] Arba Minch Ethiopia [35] Mekelle city Tigray but significant at 24-30 years age group [24] inconsistent with study done in Southeast Nigeria [21] younger age groups were aware than those elderly.

This can be explained by the fact that increased awareness among older women may be related to their own experiences of pregnancy and delivery which is an important source of their information, especially those who had complications associated with their pregnancy.

Level of maternal educational was one of the factors that statistically associated with awareness of danger sign of pregnancy. This finding is consistent with study done in parts of Ethiopia, Tsegedi district [4] Debark town north west [10], Debra Birhan town [16] Arba Minch [35] East Gojjam Zone [38] and Alexandria, Egypt [11], Tanzania [13], KwaZulu-Natal [24] Jordan [36] Narayana Medical college hospital, India [41] BRD Medical College, Gorakhpur, India [34] Debaytilatgin District [39].

This might be due to the fact that educated women have better access to reproductive health related information than those non educated women.

Current residence of the study subjects was statistical associated with DSP. Those mothers who were living in rural residents were 2.79 times more likely $[\mathrm{AOR}=2.793,95 \%$ CI $(1.686,4.626)]$ to have good awareness than those urban residents.

This finding is inconsistent with study done in other part of Ethiopia, Debra Birhan town [16], Aleta Wondo [18] and in India, Narayana Medical college hospital [41].

This difference is may be rural residents were informed about danger sign of pregnancy at home by health extension workers as well by health professionals in health facilities. Furthermore, the rural community may have history of common maternal loss due to pregnancy related problems and complications.

This study further revealed the association between DSP and place of most recent delivery of babies. Mothers who gave birth in health centres were 3.414 times more likely $[\mathrm{AOR}=3.414,95 \% \mathrm{CI}(1.078$, 10.814)] and those gave birth in private hospitals were 5.514 times more likely $[\mathrm{AOR}=5.514,95 \% \mathrm{CI}(1.551,19.601)$ to have good awareness than those gave birth their most recent delivery at home. This finding is consistent with study done in Tsegedi district [4] Tanzania [13] East Gojjam Zone Ethiopia [38].

This is may be due to the fact that mothers who were given birth in health facilities were informed about DSP and its impact in pregnancy, labour and delivery as well after child birth than those mothers who gave birth at home by traditional birth attendants. Besides, mothers may see other labouring mother facing trouble by DSP.

Furthermore, mother who did not know that DSP causes problem or death to the mother had statistical association with awareness of DSP. This finding consistently associated with study done in other part of Ethiopia, Debra Birhan town [6] Aleta Wondo, Southern, [18] East Wollega, Ethiopia [19] Arba Minch [35].

This is may be due to the fact that mothers who were given birth in health facilities were informed about DSP and may see mothers who were admitted with DSP and may understand its impact on pregnancy, labour and delivery as well after child birth than those mothers who gave birth at home by traditional birth attendants.

\section{Conclusion}

Awareness on danger signs of pregnancy among women in Diredawa administration was poor even if they are informed about DSP. Maternal age, educational level, residents, place of most recent delivery and danger sign causes problem or death to the mother were independently associated with awareness of women about DSP. Thus, provision of information, education and communication targeting women, family and the general community on DSP and associated factors is recommended.

\section{Recommendations}

Proper emphasis should be given for awareness of danger sign of pregnancy. Therefore we would like to recommend that Diredawa University College of Medicine and Health Science College in collaboration with regional health bureau, health facilities, minister of education and other concerned stakeholders' to empower women through education. Similarly, minister of health, the regional health office, zonal administrative health facilities and other responsible bodies should make efforts to provide more information about DSP by:

Scaling up of health care providers (midwives, nurses, health extension professionals) knowledge and skill by providing training on how to counsel and inform the mothers about DSP.

Preparing and providing pamphlets, broachers that are supported by pictures in order to make easy transfer of information.

A comparative study can be done between rural and urban set up.

Further study needs to be conducted at community level for better generalization.

\section{Limitation of the Study}

The findings may not be generalizable to the women who did not visit health institution.

By virtue, this study is expected to be prone for the limitation of cross sectional survey or establishing causal relationship is impossible and the wider confidence interval observed with some variables may also indicate inadequate sample size. 
Citation: Abdurashid N, Ishaq N, Ayele K, Ashenafi N (2018) Level of Awareness on Danger Signs During Pregnancy and Associated Factors, among Pregnant Mothers, Dire Dawa Administrative Public Health Facilities, Eastern Ethiopia. Clinics Mother Child Health 15: 290. doi: $10.4172 / 2090-7214.1000290$

Page 11 of 12

\section{Acknowledgments}

We are very grateful to Diredawa University, College of Medicine and Health Sciences, for their technical support and giving clearance to conduct this study.

I would like to express my gratitude to Dr. Catherine Chojenta who wakes me up from deep sleep and for her valuable encouragement to publish this paper.

\section{Availability of Data and Materials}

Data will not be share in order to protect the participants' anonymity.

\section{Authors' Contributions}

NA designed the study, performed the statistical analysis and drafted the manuscript. NI, KA and NA participated in the study design, implemented the study, and contributed to the draft manuscript. All the authors contributed to the data analysis, read and approved the final manuscript.

\section{Competing Interests}

We declare that we have no conflicts of interest to disclose.

\section{Ethics Approval and Consent to Participate}

Ethical clearance was obtained from the Institutional Research Ethics Review of Diredawa University, College of Medicine and Health Sciences. Voluntary verbal consent was obtained from each study participant.

\section{References}

1. WHO, UNICEF, UNFPA, World Bank Group, United Nations (2015) Trends in Maternal Mortality: 1990 to 2015.

2. Central Statistical Agency, ICF (2016) Ethiopian Demographic Health Survey 2016. Addis Ababa, Ethiopia, and Rockville, Maryland, USA.

3. UNICEF Data: Monitoring the Situation of Children and Women (2015) Current status progress. Maternal mortality fell by almost half between 1990 and 2015.

4. Hailu D, Berhe H (2014) Knowledge about Obstetric Danger Signs and Associated Factors among Mothers in Tsegedie District, Tigray Region, Ethiopia 2013: Community Based Cross-Sectional Study. PLoS One 9: e83459.

5. Bogale D, Marqos D (2015) Knowledge of obstetric danger signs among child bearing age women in Goba district, Ethiopia.: a cross-sectional study. BMC Pregnancy Childbirth 15: 77.

6. USAID (2008) Working toward the goal of reducing maternal and child mortality: USAID programming and response to FY08 appropriations.

7. Moran AC, Sangli G, Dineen R, Rawlins B, Yaméogo M, et al. (2006) Birth preparedness for Maternal health: Findings from Koupéla District, Burkina Faso. J Health Popul Nutr 24: 489-497.

8. United Nations Population Fund (2003) Annual Report. UNFPA 36.

9. Mahalingam G, Venkateasan M (2014) Mother's Knowledge of Warning Signs of Pregnancy, Labour and Puerperium. Int J Med Sci Public Health 3: 720-722.

10. Mengesha E, Taye H (2015) The Level of Awareness on Danger Signs of Pregnancy and Associated Factors among ANC Attendant Pregnant Women in Debark Town, North West Ethiopia 2012. Glob J Publ Health Epidemiol 2: 106-113.
11. Rashad WA, Essa RM (2010) Women's Awareness of Danger Signs of Obstetrics Complications. J Am Sci 6.

12. Fraser M, Cooper A. Myles (2003) Textbook for Midwives. 14thed. Churchill Livingston, Edinburgh.

13. Pembe AB, UrassaDP, Carlstedt A, Lindmark G, Nyström L, et al. (2009) Rural women's awareness of danger signs of obstetric complications in Tanzania. BMC Pregnancy Childbirth 9: 12.

14. Hiluf M, Fantahun M (2008) Birth Preparedness and Complication Readiness among women in Adigrat town, north Ethiopia. Ethiop J Health Dev 22: 14-20.

15. Kabakyenga JK, Östergren PO, Turyakira E, Pettersson KO (2011) Knowledge of obstetric danger signs and birth preparedness practices among women in rural Uganda. Reprod Health 8: 33.

16. Solomon AA, Amanta NW, Chirkose EA, Badi MB (2015) Knowledge About Danger Signs of Pregnancy and Associated Factors Among Pregnant Women in Debra Birhan Town, Central Ethiopia. Sci J Public Health 3: 269-273.

17. Central Statistical Agency, ORC Macro (2012) Ethiopia Demographic and health survey (2011) Addis Ababa: USAID.

18. Hailu M, Gebremariam A, Alemseged F (2010) Knowledge About Obstetric Danger Signs Among Pregnant Women In Aleta Wondo District, Sidama Zone, Southern Ethiopia. Ethiop J Health Sci 20: 25-32.

19. Wanboru AW (2013) Awareness Of Danger Signs Of Obstetric Complications Among Pregnant Women Attending Antenatal Care In East Wollega, Ethiopia. University of South Africa, Pretoria.

20. Mwilike B (2013) Knowledge of danger signs during pregnancy and subsequent health seeking actions among women in Kinondoni municipality, Tanzania. Makerere University's Institutional Repository $1-56$.

21. Ossai EN, Uzochukwu BS (2015) Knowledge of Danger Signs of Pregnancy among Clients of Maternal Health Service in Urban and Rural Primary Health Centres of Southeast Nigeria. Community Med Health Educ 5: 2 .

22. Fawole AO, Okunlola MA, Adekunle AO (2008) Clients' perceptions of the quality of antenatal care. J Natl Med Assoc 100: 1052-1058.

23. Gebrehiwot H, Bahta S, Haile N (2014) Awareness of danger signs of pregnancy and its associated factors among pregnant women who visited ANC in Mekelle public hospitals. Am J Adv Drug Deliv 2: 164-173.

24. Abiyot T, Kassa M, Buruh G, Kidanu K (2015) Awareness of Obstetric Danger Signs and its Associated Factors among Pregnant Women in Public Health Institutions, Mekelle City, Tigray, Ethiopia 2014. J Pregnancy Child Health 2: 3 .

25. Agarwal S, Sethi V, Srivastava K, Jha PK, Baqui AH (2010) Birth Preparedness and Complication Readiness among Slum Women in Indore City, India. J Health Popul Nutr 28: 383-391.

26. Baya B, Sangli G, Maiga A (2004) Measuring the effects of behaviour change interventions in Burkina Faso with population-based survey results. Maryland, USA: JHPIEGO.

27. Becker FF, Yglesias C (2004) Measuring the effects of behaviour change and service delivers interventions in Guatemala with population-based survey. Maryland: JHPIEGO.

28. S.S. Medical College (2009) Study for assessing birth preparedness and complication readiness intervention in the Rewa district of Madhya Pradesh, India. National Institute of Health and Family Welfare.

29. Afolabi BM, Ezedinachi ENU, Opara S, Arikpo I, Ogunwale A (2016) Perception of obstetric danger signs among women living on the coastline of the Atlantic Ocean in rural Lagos, Nigeria. J Public Health Epidemiol 8: $1-11$.

30. L Kumbani (2002) The knowledge of obstetric complications among primigravidae in a rural health centre in the district of Blantyre, Malawi. Curationis 25: 43-54.

31. Mbalinda SN, Nakimuli A, Kakaire O, Osinde MO, Kakande N, et al. (2014) Does knowledge of danger signs of pregnancy predict birth preparedness? A critique of the evidence from women admitted with pregnancy complications. Health Res Policy Syst 12: 60. 
Citation: Abdurashid N, Ishaq N, Ayele K, Ashenafi N (2018) Level of Awareness on Danger Signs During Pregnancy and Associated Factors, among Pregnant Mothers, Dire Dawa Administrative Public Health Facilities, Eastern Ethiopia. Clinics Mother Child Health 15: 290. doi: $10.4172 / 2090-7214.1000290$

Page 12 of 12

32. Duysburgh E, Ye M, Williams A, Massawe S, Sie A, et al. (2013) Counseling on and women's awareness of pregnancy danger signs in selected rural health facilities in Burkina Faso, Ghana and Tanzania. Trop Med Int Health 18: 1498-1509.

33. Urassa DP, Pembe AB, Mganga F (2012) Birth preparedness and complication readiness among women in Mpwapwa district, Tanzania. Tanzan J Health Res 14.

34. Sangal R, Srivastava R, Singh K, Srivastava DK, Khan H (2013) Knowledge on Components of ANC Care \& their Utilization in Women attending ANC Clinic at BRD Medical College, Gorakhpur. JARMS 5 : 159-163.

35. Workineh Y, Hailu D, Gultie T, Degefu N, Mihrete M, et al. (2014) Knowledge of obstetric danger signs and its associated factors in Arba Minch town, Ethiopia. Am J Health Res 2: 255-259.

36. Okour A, Alkhateeb M, Amarin Z (2012) Awareness of danger signs and symptoms of pregnancy complication among women in Jordan. Int J Gynaecol Obstet 118: 11-14.
37. Coleman A (2014) The Use of ICT Tools (Mobile Phones) to Improve Awareness of Pregnancy Danger Signs among Pregnant Women in Rural Communities of South Africa. J Communication 5: 203-209.

38. Amenu G, Mulaw Z, Seyoum T, Bayu H (2016) Knowledge about Danger Signs of Obstetric Complications and Associated Factors among Postnatal Mothers of Mechekel District Health Centers, East Gojjam Zone, Northwest Ethiopia. Scientifica 3495416: 7.

39. Dile M, Taddesse D, Gedefaw M, Asmama T (2015) Knowledge of Obstetric Danger Signs and its Associated Factors in Debaytilatgin District, Ethiopia A Community Based Cross Sectional Study. Gynecol Obstet 5: 9.

40. Hoque M, Hoque ME (2011) Knowledge of Danger Signs for Major Obstetric Complications among Pregnant KwaZulu-Natal Women: Implications for Health Education. Asia Pac J Public Health 23: 946-956.

41. Hymavthi K, Shilpa R, Tom SC, Indira S, Shaik AB, et al. (2013) A primary investigation to assess the knowledge of "warning signs in pregnancy” among Antenatal women. J Pharma Res Dev 2: 249-253. 